\title{
Reliving, Emotions, and Fragmentation in the Autobiographical Memories of Veterans Diagnosed with PTSD
}

\author{
DAVID C. RUBIN ${ }^{1} *$, MICHELLE E. FELDMAN ${ }^{2}$ and \\ JEAN C. BECKHAM ${ }^{2,3}$ \\ ${ }^{1}$ Duke University, USA \\ ${ }^{2}$ Durham Veterans Affairs Medical Center, USA \\ ${ }^{3}$ Duke University Medical Center, USA
}

\begin{abstract}
SUMMARY
Fifty veterans diagnosed with posttraumatic stress disorder (PTSD) each recalled four autobiographical memories: one from the 2 years before service, one non-combat memory from the time in service, one from combat, and one from service that had often come as an intrusive memory. For each memory, they provided 21 ratings about reliving, belief, sensory properties, reexperiencing emotions, visceral emotional responses, fragmentation, and narrative coherence. We used these ratings to examine three claims about traumatic memories: a separation of cognitive and visceral aspects of emotion, an increased sense of reliving, and increased fragmentation. There was evidence for a partial separation of cognitive judgments of reexperiencing an emotion and reports of visceral symptoms of the emotion, with visceral symptoms correlating more consistently with scores on PTSD tests. Reliving, but not fragmentation of the memories, increased with increases in the trauma relatedness of the event and with increases in scores on standardized tests of PTSD severity. Copyright (C) 2004 John Wiley \& Sons, Ltd.
\end{abstract}

We examine three issues of theoretical importance in posttraumatic stress disorder (PTSD): first, a stronger sense of reliving in autobiographical memories; second, differences in the way the cognitive and visceral aspects of emotion interact with other properties of autobiographical memory; third, fragmentation and a lack coherence in autobiographical memories.

\section{RELIVING}

A sense of reliving is a complex concept in psychology and philosophy (see Brewer, 1996, for a review), varying from the disturbingly intense flashbacks of PTSD to the milder recollection of a subject in a word-list experiment who makes a remember versus know judgment. Nonetheless, for many, a sense of reliving is viewed as a defining feature of

\footnotetext{
*Correspondence to: Professor David C. Rubin, Department of Psychological and Brain Sciences, Duke University, Durham, NC 27708-0086, USA. E-mail: david.rubin@duke.edu

Contract/grant sponsor: NIH grant R01 MH62482.
}

Copyright (C) 2004 John Wiley \& Sons, Ltd. 
autobiographical memory (Baddeley, 1992; Brewer, 1996; Rubin, 1998; Tulving, 1983, 1985; Wheeler, Stuss, \& Tulving, 1997) and the involuntary reliving of autobiographical memories is part of the diagnosis of PTSD. In particular, the criterion for PTSD include that 'the traumatic event is persistently reexperienced in one (or more) of the following ways: (1) recurrent and intrusive recollections of the event.... (3) acting or feeling as if the traumatic event were recurring' (American Psychiatric Association, 1994, pp. 427-428).

In contrast to the high degree of involuntary reliving of the memories in the official diagnosis of PTSD, for the voluntary retrieval of traumatic memories, no strong prediction can be made. The flashbulb memory literature predicts an increased sense of reliving for traumatic events (Brown \& Kulik, 1977). On the other hand, a clinical perspective would predict a decreased sense of reliving produced by a fluctuation between involuntary intrusion and voluntary avoidance of the memory (Brewin, Dalgleish, \& Joseph, 1996; Horowitz \& Reidbord, 1992), at the extreme resulting in functional amnesia for the trauma (American Psychiatric Association, 1994; Christianson \& Nilsson, 1989; Elliot, 1997). Empirically, when compared to memories that are intended to be of equal emotional intensity, the general finding is that voluntary traumatic memories are relived to an equal or lesser degree. Byrne, Hyman, and Scott (2001) had participants compare their worst traumatic event with a very negative and very positive event of the same time period. They did not ask directly about a sense of reliving, but did ask about sensory qualities and emotional intensity at recall. There were often no differences in their measures, but when there were, traumatic memories were never the most emotionally intense. Tromp, Koss, Figueredo, and Tharan (1995) asked participants to rate memories of rape or 'another intense life event and to indicate whether it was pleasant or unpleasant' (p. 613). On measures related to a sense of reliving, rape memories were always numerically lower. Similarly, Porter and Birt (2001) found no differences on ratings of the vividness of the memory, but found sensory qualities for most traumatic experiences lower than for most positive experiences.

We compare four memories that vary in the degree to which they are trauma related. Unlike the studies just reviewed, we do not try to control for the emotional intensity of the memories, which are often an integral aspect of the trauma-related memories; therefore, whatever effects we get may be due to emotional intensity independent of any traumatic component. To counter this problem, we also do analyses in which we compare the ratings on measures of a sense of reliving of participants with varying PTSD symptom severity. Using a similar analysis, Berntsen, Willert, and Rubin (2003) found higher ratings of reliving for trauma-related memories in participants who had PTSD symptoms than in those who did not. We also ask questions to assess belief in the accuracy of the memory so that we can ensure that any increases in reliving we observe are not due to an overall tendency to rate the phenomenological properties of the traumatic events more highly. That is, we wish to be able to show that reliving acts differently than belief in the accuracy of the memory to show the effects we find for reliving are at least somewhat specific to reliving. We chose belief that the memory actually occurred the way it was remembered and was not imagined because this is a central phenomenological property of autobiographical memory (Brewer, 1996) that has attracted much attention in the autobiographical memory literature (Hyman, Gilstrap, Decker, \& Wilkinson, 1998; Johnson, Foley, Suengas, \& Raye, 1988; Ross, Buehler, \& Karr, 1998). We also include measures of the sensory components of the memory in several modalities, as these are often included in definitions of a sense of reliving and flashback in the PTSD literature. 


\section{EMOTIONS}

It is common to note that the visceral aspects of emotions are often independent of and not always accessible to conscious reflection or judgment (e.g. Lambie \& Marcel, 2002), and that this occurs specifically for fear (LeDoux, 1989) and trauma (Brewin et al., 1996; Kolb \& Mutalipassi, 1982). In addition, network theories of PTSD (e.g. Foa \& Kozak, 1986; Pitman, 1988; Pitman, Orr, \& Steketee, 1989) deal primarily with physiological responses and so comparing reports of such responses to a more cognitive judgment of emotion would be useful. To attain rating scales that would separate visceral from cognitive aspects of emotion, we asked our participants to report on visceral emotional responses in addition to the more cognitive or reflective question of whether they experienced the emotion again. In this way, we hoped to see if these two aspects of emotions change in similar ways with the type of memory and whether they have similar relations to the other variables we measure. We chose the rating scales to involve either as little or as much higher-level cognitive processing and insight as possible. Reporting on ongoing visceral sensations such as feeling your heart pound, feeling sweaty, feeling tense, or having butterflies in your stomach are about as direct a report as possible. In contrast, answering whether the emotion at remembering is the emotion felt at the time of the event requires constructing or remembering the original emotion and classifying it, being aware of and classifying your current emotion, and comparing the two.

\section{FRAGMENTATION}

In examining the theoretical issue of fragmentation, two claims need to be separated. One claim is that the memories of trauma are not integrated into the life story of the person and thus cause problems (Brewin et al., 1996; Horowitz, 1975; Horowitz \& Reidbord, 1992). We will not examine this issue empirically here, but note that the opposite might be true. Having a traumatic event or period integrated into one's life so that it is central to one's life story may have adverse effects for memory (McNally, Lasko, Macklin, \& Pitman, 1995) and may be associated with PTSD symptoms (Berntsen et al., 2003). For instance, Byrne et al. (2001) found a 0.35 correlation between a PTSD symptom checklist and ratings of whether the traumatic memory was important to understanding the self. The other claim, which we do examine, is that the memories themselves are not an integrated whole; they lack narrative coherence and often come in pieces with important aspects missing (Foa, Molnar, \& Cashman, 1995; Nijenhuis \& Van der Hart, 1999). For instance, van der Kolk and Fisler (1995) participants' in retrospect reported that their memories of trauma were initially less coherent than they are now. In such primary dissociation (Van der Hart, Van der Kolk, \& Boon, 1998), some components of the original traumatic event may be isolated and inaccessible for conscious retrieval, whereas others may be highly salient and vividly relived.

In contrast to the clinical observations, there is little experimental support for the idea that memories of traumatic experiences for all people, or for people with PTSD, are less coherent and more fragmented. Byrne et al. (2001) found no difference among traumatic, positive, and negative memories in the ratings of undergraduates who had had a trauma in whether the order of the events in the memory was confusing or comprehensible. Porter and Birt (2001) also found no differences in coherence between traumatic and positive memories as measured by independently judged scores of coherence. Comparing participants with and without PTSD symptoms, Berntsen et al. (2003) found no differences in participants' ratings of coherence of memories for traumas. 
The most complete design addressing this question is by Gray and Lombardo (2001). They investigated whether the lower coherence in narratives of trauma in people with PTSD found by Amir, Stafford, Freshman, and Foa (1998) was due to the lower verbal abilities typically found in people diagnosed with PTSD. They replicated the Amir et al. (1998) finding but found that once verbal abilities were controlled, the difference in coherence disappeared. Moreover, Gray and Lombardo had participants record a pleasant and an unpleasant memory in addition to the memory for a trauma. Counter to the fragmentation hypothesis, they found no interaction between people diagnosed with and without PTSD and the coherence of the three types of memories. Taken together these studies do not offer support for the idea that people with PTSD have memories for trauma that are more fragmented and less coherent than people without PTSD or for the idea that memories for trauma are more fragmented and less coherent than other memories for either PTSD or non-PTSD diagnosed populations.

None of the studies that used rating scales of the participants' own perception of the coherence of their memories tested people who were actually diagnosed with PTSD. Different aspects of coherence are measured by the rating scales of participants and objective measures of coherence done by neutral observers or linguistic analysis; it is important to know whether the memory is complete, makes sense, and is easy to follow from both a first person and a third person perspective (Robinson, 1996). To supplement the existing literature, we therefore asked our participants questions about the narrative coherence and fragmentation of their own memories.

\section{ANALYSIS STRATEGY}

We do analyses in two different ways. First, we do analyses based on the nature of the memory being recalled; whether it was a memory from the 2 years prior to military service, from non-combat, from combat, or a memory from military service that has come as an intrusive memory. We expect pre-military and non-combat memories to be of less stressful and less trauma-related events than combat and intrusive memories and so expect to be able to have a dichotomous scale of trauma-like events. Second, we consider the different kinds of autobiographical memories as a sample of autobiographical memory retrieval and group them, asking about the effects of individual differences in severity of PTSD symptoms and dissociation. Thus, we ask about our three theoretical claims in two ways. The first is whether memories of more trauma-related events show differences on the relevant rating scales. The second is whether people who have more severe symptoms of PTSD show differences on the relevant rating scales. Combining both the experimental and individual differences approach provides converging evidence for key theoretical issues and for our description of autobiographical memory (Cronbach, 1957). For alternative approaches using multiple levels of analysis see Wright (1998).

\section{THE AUTOBIOGRAPHICAL MEMORY QUESTIONNAIRE AND INDIVIDUAL DIFFERENCES SCALES}

We included five rating scales to measure a sense of reliving and belief in the accuracy of the memory, two concepts where the reports of our participants are the ultimate standard. Three rating scales were intended to assess a sense of reliving because it is a defining 
feature of autobiographical memory and of PTSD. The first rating scale asked whether the participants felt as though they were reliving the original event. The second was taken specifically from work by Tulving and his colleagues (e.g. Wheeler et al., 1997), and asked whether the memory came with a sense of mentally traveling back in time to the original experience. The third formulation asked whether the participants could remember the event, or if they simply knew it had happened (remember); it is adapted from earlier work by Tulving (1985) and from the extensive empirical and theoretical work by Gardiner and colleagues and others in laboratory recognition tasks (e.g. Gardiner, Ramponi, \& Richardson-Klavehn, 1998), in autobiographical memory experiments (Hyman et al., 1998; Rybash \& Monaghan, 1999), and in laboratory recognition tasks manipulating references to the self (Conway \& Dewhurst, 1995; Hirshman \& Lanning, 1999). We included two rating scales to measure belief by asking our participants to judge whether the event really occurred in the way it was remembered, or whether some parts of the memory had been imagined (our real variable) and whether they could be persuaded that it did not happen as they recalled it (our persuade variable). In contrast to a sense of reliving, belief in the accuracy of memories is not a distinguishing clinical feature of PTSD, though it is a central property of autobiographical memories; autobiographical memories are, in general, believed to be accurate (Brewer, 1996).

Having considered two fundamental properties of autobiographical memory (a sense of reliving and belief) we turn to properties that can be seen as component processes involved in having and reporting an autobiographical memory; though in the context of PTSD, the sensory and emotional components are also used as a marker of a sense of reliving and flashbacks. The most important of the component processes in the psychological and philosophical literatures is visual imagery (Brewer, 1996; Greenberg \& Rubin, 2003; Rubin, 1998; Rubin \& Greenberg, 2003). Visual imagery can be divided on behavioural and neural grounds into two systems: object or descriptive imagery and spatial imagery. More colloquially, these comprise a 'what' and a 'where' system (Farah, Hammond, Levine, \& Calvanio, 1988; Greenberg \& Rubin, 2003; Rubin, 1995a). By using a rating scale that asks whether the event can be seen in the mind, we measure visual imagery with emphasis on its descriptive component (our see variable). By asking whether the setting can be recalled, we measure visual imagery with emphasis on the spatial component (our setting variable). The latter question can also be seen as a measure of context or as one aspect of the genre of telling a coherent story.

We asked whether the memory could be heard in the mind (our hear variable) to contrast visual imagery from imagery in general, because of the interest in auditory imagery (Reisberg, 1992), and because of the role of auditory imagery in language, and we also asked about olfaction (our smell variable). Autobiographical memories often contain reports of language, and language is the most common way to communicate autobiographical memories. Because of the central role of language in cognition and in culture (Schrauf, 2000; Schrauf \& Rubin, 1998, 2000), we included two questions on language that have an auditory imagery component. These questions ask whether people are talking in the memory (our talk variable) and whether the memory comes in words. For PTSD, having a memory come in words instead of images may be a way of distancing oneself from the sensory components of the event (Foa \& Kozak, 1986). Because of the important role that narrative coherence plays in autobiographical memory (see Rubin, 1995b, 1998, for reviews) and PTSD and because narrative can be viewed as independent of language (Greenberg \& Rubin, 2003; Rubin \& Greenberg, 2003), we formulated one question directly about narrative coherence. It asked our participants to report whether the memory 
was coherent or whether it came in isolated facts or observations, independent of whether the memory came mostly in words or in images (our story variable). A related question asked the reverse, focusing on fragmentation, that is, whether the memory came in pieces with parts missing. We also asked whether the memory was specific to the participant's life as opposed to being an event anyone might infer from a general life story.

In addition to the more traditionally cognitive properties we have just described, it is clear that emotions play an important and actively researched role in autobiographical memory (Christianson, 1992; Christianson \& Safer, 1996) and PTSD. As reviewed earlier, we therefore asked questions about both the cognitive and visceral aspects of emotion. At the visceral level we asked about four specific visceral reactions that have been used in the script-driven imagery procedure (Pitman et al., 1990), and that were used in a large scale study examining trauma imagery and psychophysiological responses in PTSD (Keane et al., 1998).

Because rehearsal, especially spaced rehearsal (Bahrick, 1979; Rubin, 1995a), improves retention, because the report of such rehearsal varies for different types of cues (Rubin, Groth, \& Goldsmith, 1984), and because in many models rehearsal can lead to the development of a schema or to the transfer to semantic memory, we asked participants to estimate the number of times they had previously thought about the memory. In terms of PTSD, thinking about a memory may be an indication of intrusive memory severity. For instance, Horowitz (1975) proposed an active memory storage, which repeats its own content until processing is completed. Efforts at avoiding such conscious recollections of the trauma lead to a fluctuation between intrusive memories and avoidance (Horowitz \& Reidbord, 1992).

We included two different measures of PTSD severity and one of dissociation. The Davidson Trauma Scale (DTS) (Davidson et al., 1997) asks for the frequency and severity of 17 symptoms that closely follow those in the DSM-IV (American Psychiatric Association, 1994), and thus provides separate measures for the B (reliving) $\mathrm{C}$ (avoidance and numbing) and D (hyperarousal) symptoms of PTSD. The scale has high reliability and validity across trauma populations (Davidson et al., 1997). The Mississippi Scale for Combat-Related PTSD (Keane, Caddell, \& Taylor, 1988) differs in that it was developed specifically for combat veterans and its 35 items, many of which refer directly to military service, do not follow the DSM-IV manual as closely. Rather participants are asked to endorse items on a 5-point scale from not at all true to extremely true. The items were selected by clinicians familiar with combat PTSD and include measures of behaviours or conditions that are typically comorbid with PTSD in combat veterans including substance abuse and depression. It has been found to yield reliable and valid scores in both clinical and community samples (Keane et al., 1988). The Dissociative Experiences Scale (DES) is a standardized test of dissociation and one of the most used test in individual difference studies of autobiographical memory, where it is often correlated with suggestibility (Read \& Winograd, 1998; Wright \& Livingston-Raper, 2002). Scores below 10 suggest normal levels of dissociation whereas scores above 30 are considered indicative of a dissociative disorder or PTSD. The DES yields internally consistent and stable scores (Bernstein \& Putnam, 1986; Carlson \& Putnam, 1993). In addition, it has been found to effectively discriminate patients with dissociative disorders from those with other psychiatric disorders (Carlson \& Putnam, 1993). We include it here not only because of its ability to predict which people are more likely to be able to be induced to have false memories but also to see if the effects of PTSD severity and dissociation are different. That is, we wish to show that PTSD severity has unique effects. 


\section{METHOD}

\section{Participants}

We included the 50 consecutive male help-seeking veterans being screened at the Durham Veterans Affairs Medical Center who 1) completed the form described in the next section, 2) at the time they were being evaluated for PTSD, and 3) who later received a diagnosis of PTSD based on a standard battery of tests and clinical interviews. Their average age was $50(S D=8.5$, range of 25 to 78$)$. The mean scores on the DTS, Mississippi PTSD scale, and DES are as follows: DTS total $(94, S D=29$, range of 31 to 136$)$, DTS B $(28, S D=10$, range of 2 to 40$)$, DTS C ( $35, S D=13$, range of 8 to 56), DTS D (31, $S D=9$, range of 8 to $40)$, Mississippi PTSD scale $(125, S D=20$, range of 81 to 158$)$, and DES (42, $S D=22$, range of 9 to 86 ).

\section{Procedure}

Clinical testing for the diagnosis of PTSD occurred over two assessment days. On the first assessment day, participants completed self-report questionnaires and demographic information. The order of the tests was demographic information first, then the DES, the Mississippi PTSD scale, the DTS, and the Autobiographical Memory Questionnaire. On the second assessment day, participants completed the Clinician Administered PTSD Scale (Blake et al., 1995) with a trained clinician, which was the basis for the diagnosis of PTSD.

For the Autobiographical Memory Questionnaire, we asked for four kinds of memories, always in the same order. We kept the order fixed for two reasons. First, we wanted to compare the results we obtained with individual differences measures and so wanted to introduce as little variation among participants as possible. Second, we thought that by asking participants to first recall memories for events that were likely to be less emotional, we would minimize the effects of each memory on the next. The four cues for memories were as follows. 1. Pre-service: 'Please think about a specific event that happened to you in the year or two before you entered the military'. 2. Non-combat: 'Please think about a specific event that happened to you while you were in the military, but not during combat'. 3. Combat: 'Please think about a specific event that happened to you while you were in the military during combat'. These first three cues were all followed by the following sentence: 'Please try to keep this memory in mind when you answer the questions that follow on this page and the next'. 4. Intrusive: 'Some veterans continue to have memories or flashbacks about traumatic events that occurred to them in the military even though they do not want to. If such memories or flashbacks come to you, please answer the following questions thinking about what it feels like when it happens. Please use your most common memory of this type in answering this question. If it does not occur, please skip the rest of this page and the next'. Although we asked about an involuntary memory, we obtained a voluntary retrieval of that memory. We therefore treat the ratings obtained as highly influenced by the current voluntary retrieval, not as rating from an actual involuntary memory. The similarity of the responses to these memories and the combat memories of the previous question, to be shown later, support this assumption.

For each of these memories, the following 21 7-point rating scale questions were asked in the order that follows. Most of the questions are from the Autobiographical Memory Questionnaire we have used elsewhere (Rubin, Schrauf, \& Greenberg, 2003; Sheen, 
Kemp, \& Rubin, 2001; Talarico \& Rubin, 2003) with additional questions on emotions. Each question had boldfaced underlined key words, which are underlined here and used as the basis of labels for the question in the tables. 1. While remembering the event, I feel as though I am relivingit. 2. While remembering the event, I can hear it in my mind. 3. While remembering the event, I can see it in my mind. 4. While remembering the event, I can smell it in my mind. 5. While remembering the event, I or other people are talking. 6. While remembering the event, I feel the emotions I felt then. 7. I believe the event in my memory really occurred in the way I remember it and that I have not imagined or fabricated anything that did not occur. 8. My memory comes in pieces with missing bits. 9 . While remembering the event, it comes to me in words. 10. While remembering the event, I feel that I travel back to the time when it happened, that I am a participant in it, rather than an outside observer tied to the present. 11. While remembering the event, it comes to me in words or in pictures as a coherent story or episode and not as an isolated fact, observation, or scene. 12. While remembering the event, I know the setting where it occurred. 13. As I think about the event, I can actually remember it rather than just knowing that it happened. 14. My memory is based on details specific to my life, not on general knowledge that I would expect most people to have. 15. Since it happened, I have thought or talked about this event (labelled as rehearse in the tables). 16. If another $\overline{\text { witness }}$ to the event, who you generally trusted, existed and told you a very different account of the event, to what extent could you be persuaded that your memory of the event was wrong. 17. While remembering the event, I feel happy. 18. While remembering the event, I feel my heart pound, race, or quicken. 19. While remembering the event, I feel sweaty or clammy. 20. While remembering the event, I feel tense all over. 21 . While remembering the event, I feel knots, butterflies or cramps in my stomach.

Questions 1 to 6 and 12 were answered on scales anchored at $1=$ not at all and $7=$ as clearly as if it was happening now. Question 7 was anchored at $1=100 \%$ imaginary and $7=100 \%$ real. Questions 8 to 11 and 13,14 , and 16 were anchored at $1=$ not at all and $7=$ completely. Question 15 was anchored at $1=$ not at all and $7=$ as often as any event in my life. Questions 17 to 21 were anchored at $1=$ not at all and $7=$ as much as any memory.

\section{RESULTS}

\section{Analysis of the four memory cues}

For each type of memory, Table 1 presents the means and standard errors for each rating scale, as well as the results of analyses of variance (ANOVA) and planned comparisons of adjacent types of memories. For 17 of the 21 memory rating scales there is a significant overall effect of type of memory. In general, for these 17 memory rating scales, there is a monotonic increase (or decrease for happy) from pre-service to non-combat to combat to intrusive memories. For 12 of these 17 memory rating scales the progression is strictly monotonic and for the remaining five there is an inversion with combat being numerically higher (but not statistically different from) intrusive memories. Thus, in addition to statistically significant $F$ ratios, the pattern of means is reasonable. Moreover, for the 17 rating scales that show a significant difference, the pre-service and non-combat memories are lower (or higher for happy) than the other two memories. In addition, the major difference, on the 17 rating scales where the difference was significant, is between the pre- 
Table 1. Means and standard errors of ratings for autobiographical memories

\begin{tabular}{lllllll}
\hline Variable & $\begin{array}{l}\text { Pre-service } \\
\text { Mean (SE) }\end{array}$ & $\begin{array}{c}\text { Non-combat } \\
\text { Mean (SE) }\end{array}$ & $\begin{array}{c}\text { Combat } \\
\text { Mean (SE) }\end{array}$ & $\begin{array}{c}\text { Intrusive } \\
\text { Mean (SE) }\end{array}$ & $F(3,147)$ & $\eta^{2}$ \\
\hline Relive & $3.60(0.31)^{* *}$ & $4.48(0.29)^{*}$ & $5.06(0.31)$ & $5.20(0.27)$ & $10.79^{* * *}$ & 0.08 \\
Back in time & $3.94(0.32)^{* *}$ & $4.84(0.29)^{*}$ & $5.50(0.25)$ & $5.74(0.24)$ & $16.58^{* * *}$ & 0.12 \\
Remember & $4.76(0.28)$ & $5.18(0.27)^{* *}$ & $5.68(0.24)$ & $5.78(0.23)$ & $8.86^{* * *}$ & 0.05 \\
Real & $5.18(0.30)^{*}$ & $5.94(0.23)$ & $6.18(0.22)$ & $6.08(0.23)$ & $5.44^{* *}$ & 0.05 \\
Persuade & $2.80(0.22)$ & $2.48(0.23)$ & $2.73(0.27)$ & $2.48(0.26)$ & 1.11 & 0.01 \\
See & $4.08(0.29)^{* *}$ & $4.78(0.31)^{*}$ & $5.50(0.24)$ & $5.78(0.21)$ & $16.39^{* * *}$ & 0.11 \\
Setting & $4.84(0.27)$ & $5.04(0.26)$ & $5.44(0.26)$ & $5.52(0.24)$ & $4.22^{* *}$ & 0.02 \\
Smell & $2.96(0.30)$ & $3.53(0.34)^{* *}$ & $4.47(0.32)$ & $4.80(0.31)$ & $12.64 * * *$ & 0.10 \\
Hear & $3.66(0.30)$ & $4.41(0.31)^{* * *}$ & $5.43(0.26)$ & $5.44(0.25)$ & $17.32^{* * *}$ & 0.12 \\
Talk & $3.16(0.28)$ & $3.68(0.31)^{*}$ & $4.29(0.31)$ & $4.51(0.32)$ & $7.73 * * *$ & 0.06 \\
In words & $3.16(0.27)^{*}$ & $3.88(0.29)$ & $3.96(0.32)$ & $4.24(0.31)$ & $6.65 * * *$ & 0.04 \\
Story & $3.66(0.28)$ & $3.90(0.29)^{*}$ & $4.49(0.30)$ & $4.42(0.31)$ & $4.07 * *$ & 0.03 \\
Specific & $3.68(0.31)$ & $3.57(0.33)$ & $3.49(0.34)$ & $3.67(0.35)$ & 0.55 & 0.00 \\
Pieces & $3.50(0.29)$ & $3.16(0.28)$ & $3.35(0.33)$ & $3.60(0.32)$ & 0.63 & 0.01 \\
Rehearse & $3.60(0.26)$ & $3.80(0.30)$ & $3.76(0.27)$ & $3.90(0.28)$ & 0.54 & 0.00 \\
Emotions & $3.90(0.30)^{* *}$ & $4.74(0.30)$ & $4.98(0.30)^{*}$ & $5.47(0.28)$ & $11.31 * * *$ & 0.07 \\
Happy & $2.63(0.29)$ & $2.66(0.31)^{* *}$ & $1.70(0.22)$ & $1.88(0.26)$ & $4.09^{* *}$ & 0.05 \\
Heart & $3.80(0.32)$ & $3.90(0.32)^{* *}$ & $4.76(0.29)$ & $4.58(0.30)$ & $5.90^{* * *}$ & 0.04 \\
Sweaty & $3.24(0.31)$ & $3.56(0.33)^{* *}$ & $4.36(0.32)$ & $4.32(0.33)$ & $9.46^{* * *}$ & 0.04 \\
Tense & $3.72(0.31)$ & $4.22(0.32)^{* *}$ & $5.20(0.27)$ & $5.26(0.27)$ & $12.64 * * *$ & 0.09 \\
Stomach & $3.10(0.32)$ & $3.52(0.34)^{* * *}$ & $4.68(0.33)$ & $4.68(0.33)$ & $19.58^{* * *}$ & 0.09 \\
\hline
\end{tabular}

Note: $*=0.05 ; * *=0.01 ; * * *=0.001$. The asterisks between the columns of means indicate whether the means on either side are different by a planned comparison. $\eta^{2}$ is a measure of effect size.

service and non-combat memories and the other two memories, supporting our initial plan of dichotomizing the four types of memories into more and less stressful and trauma related. The four memory rating scales that do not show a significant effect (persuade, specific, pieces, and rehearse) all have $F$ ratios near or less than 1.00 and non-monotonic patterns. This suggests that they may not be affected by type of memory as opposed to having weak effects that do not demonstrate themselves with the power available.

Turning to our three theoretical issues, for the first three variables in Table 1, which measure aspects of reliving, and the sensory variables of see, hear, and smell (which can be seen as aspects of reliving), there is a clear increase of each with increasing trauma relatedness of the memory. For the two comparison variables that measure belief, the effect is smaller, with no significant effect for persuade, and with the only significant contrast for real being between pre-service and non-combat memories. Thus there is a specific increase for reliving that cannot be due simply to the more trauma-related memories accruing indiscriminate positive judgments.

Both the cognitive and visceral emotions increase with the trauma relatedness of the memory, but they have slightly different patterns. For the visceral emotions, the preservice and non-combat memories are at about the same level and lower than the combat and intrusive memories, which also do not differ from each other. For emotions, which is the degree to which the one feels the same emotions while remembering what one originally felt, the main differences are between pre-service and non-combat and between combat and intrusive. The difference in these patterns could make sense even if the cognitive and visceral emotions were working in complete agreement as they measure different aspects of emotion; there is likely to be less visceral symptoms to report for 
pre-service and non-combat memories. Therefore the analysis presented in Table 1 does not argue for a separation in the functioning of visceral and cognitive emotions.

The results offer no support for an increase in fragmentation within memories that are more trauma related. The $F$ ratio for pieces is less than 1.00. Compared to pre-service and non-combat memories, memories of combat and memories that come as intrusive memories do not come more 'in pieces with missing bits.' Examining the means of pieces and the $F$ ratios of other questions on Table 1 indicates that the lack of significance is not a problem of insufficient power. There is a significant effect of narrative coherence as measured by story, but it goes in the wrong direction for the fragmentation hypothesis. The trend is for more trauma-related memories to be more coherent. Setting can be considered as an essential part of a good story, as opposed to a measure of spatial layout. Under this interpretation of setting, it provides similar results to story.

\section{Analysis of individual differences}

To further examine our three theoretical issues, we turn to individual differences measures. Table 2 examines the relationship among the severity of PTSD as measured by the DTS and the Mississippi Scale for Combat-Related PTSD, as well as the DES scale of dissociation. Table 3 examines the relationship of these variables with the Autobiographical Memory Questionnaire. Before examining particular correlations, some observations about Table 3 in general should be made. There are too many significant correlations to have occurred by chance. In particular, if all the measures were random and independent, by chance we would expect about 6,1 , and 0 correlations to be significant at least the $0.05,0.01$, and 0.001 level, and there are 56, 35, and 8, respectively. More importantly, the pattern of correlations is far from random: of the 24 correlations with the visceral emotions, all but one is significant; of the 12 correlations with measures of belief, none are. Except for the correlations with visceral emotions, none of the correlations with the reexperiencing subscale of the DTS are significant, and thus the correlations we do get with our autobiographical memory measures of reliving and other PTSD scales cannot be due simply to our autobiographical memory questions assessing a sense of reliving in the same way that the PTSD scales do.

Examining our three theoretical issues in turn, the three measures of a sense of reliving correlate with the DTS hyperarousal scale and the Mississippi PTSD scale. The three sensory rating scales of see, hear, and smell show a similar pattern. In contrast, the two measures of belief do not show any correlations with PTSD measures, nor does the DES scale correlate with any of the three measures of reliving or the three sensory rating scales.

Table 2. Correlations among the standardized tests

\begin{tabular}{lccccc}
\hline & \multicolumn{3}{c}{ Davidson } & \\
\cline { 2 - 4 } & Total & B & C & D & Mississippi \\
\hline Davidson B & 0.92 & & & & \\
Davidson C & 0.94 & 0.77 & & & \\
Davidson D & 0.93 & 0.81 & 0.82 & & \\
Mississippi & 0.81 & 0.68 & 0.78 & 0.78 & 0.59 \\
DES & 0.69 & 0.68 & 0.69 & 0.55 & 0.59 \\
\hline
\end{tabular}

Note: All correlations $p<0.0001$. For the Davidson, B is reliving, $\mathrm{C}$ is avoidance and numbing, and D is hyperarousal. 
Table 3. Correlations of PTSD and DES tests with ratings of autobiographical memories

\begin{tabular}{|c|c|c|c|c|c|c|}
\hline \multirow[b]{2}{*}{ Variable } & \multicolumn{4}{|c|}{ Davidson } & \multirow[b]{2}{*}{ Mississippi } & \multirow[b]{2}{*}{ DES } \\
\hline & B & $\mathrm{C}$ & $\mathrm{D}$ & Total & & \\
\hline Relive & 0.15 & 0.24 & $0.31^{*}$ & 0.25 & $0.37 * *$ & 0.07 \\
\hline Back in time & 0.21 & $0.28 *$ & $0.36 * *$ & 0.20 & $0.37 * *$ & 0.14 \\
\hline Remember & 0.10 & 0.18 & $0.31^{*}$ & 0.21 & $0.38 * *$ & 0.03 \\
\hline Real & 0.07 & 0.13 & 0.09 & 0.11 & 0.23 & 0.04 \\
\hline Persuade & 0.17 & -0.00 & 0.00 & 0.06 & -0.02 & 0.26 \\
\hline See & 0.13 & 0.27 & $0.32 *$ & 0.26 & $0.40 * *$ & 0.13 \\
\hline Setting & 0.09 & 0.19 & $0.30^{*}$ & 0.21 & $0.41 * *$ & 0.02 \\
\hline Smell & 0.26 & $0.35^{* *}$ & $0.41 * *$ & $0.37 * *$ & $0.48 * * *$ & 0.27 \\
\hline Hear & 0.20 & $0.39 * *$ & $0.39 * *$ & $0.35^{*}$ & $0.46^{* * *}$ & 0.23 \\
\hline Talk & 0.16 & $0.32 *$ & $0.31 *$ & $0.29 *$ & $0.46^{* * *}$ & $0.33^{*}$ \\
\hline In words & 0.20 & 0.26 & $0.35 *$ & $0.29 *$ & 0.26 & $0.39 * *$ \\
\hline Story & 0.06 & 0.27 & 0.18 & 0.19 & 0.23 & 0.24 \\
\hline Specific & -0.07 & 0.00 & 0.06 & -0.01 & 0.04 & 0.11 \\
\hline Pieces & 0.12 & $0.28 *$ & 0.25 & 0.24 & 0.07 & $0.42 * *$ \\
\hline Rehearse & 0.15 & $0.28 *$ & 0.20 & 0.23 & 0.10 & $0.31 *$ \\
\hline Emotions & 0.18 & 0.21 & $0.32 *$ & 0.25 & $0.37 * *$ & 0.21 \\
\hline Happy & 0.10 & 0.09 & 0.01 & 0.08 & -0.07 & -0.01 \\
\hline Heart & $0.31 *$ & $0.31 *$ & $0.39 * *$ & $0.35^{*}$ & $0.36^{*}$ & 0.23 \\
\hline Sweaty & $0.41 * *$ & $0.32 *$ & $0.47 * * *$ & $0.42 * *$ & $0.40 * *$ & $0.37 * *$ \\
\hline Tense & $0.34 * *$ & $0.38 * *$ & $0.49 * * *$ & $0.43 * *$ & $0.49 * * *$ & $0.37 * *$ \\
\hline Stomach & $0.40 * *$ & $0.41 * *$ & $0.51 * * *$ & $0.46 * * *$ & $0.39 * *$ & $0.43 * *$ \\
\hline
\end{tabular}

Note: $*=0.05 ; * *=0.01 ; * * *=0.001$. For the Davidson, $\mathrm{B}$ is reliving, $\mathrm{C}$ is avoidance and numbing, and $\mathrm{D}$ is hyperarousal.

Thus, we have support for the claim that the reliving of memories increases with the severity of PTSD symptoms and that that increase is fairly specific to reliving rather than involving phenomenological judgments about belief or individual difference measures of dissociation. Turning to the separation of visceral and cognitive emotions, the visceral emotions have large and consistent correlations with the individual differences measures. The cognitive measure, emotions, correlates with the DTS arousal subscale and the Mississippi PTSD scale. It thus appears that visceral emotions may be more related to PTSD symptom severity. We again find strong evidence against the claim of fragmentation of trauma-related memories in PTSD. All of the correlations with story, a direct measure of narrative coherence, are not significant and are positive so would be in the wrong direction for this hypothesis if they were significant. Pieces shows a significant correlation with only one PTSD measure. It has a larger correlation with DES, which is consistent with the notion of dissociation and suggests that this question is measuring what it was intended to measure, even if it does not correlate highly or consistently with measures of PTSD. Finally, the two correlations with setting that are significant are in the wrong direction for the fragmentation hypothesis.

\section{Factor analyses}

Table 4 displays three factor analyses. All are principal factor analyses with promax rotations, in which all factors with eigenvalues greater than 1.00 were retained because these analyses were easily interpretable and because there were no clear breaks in the eigenvalues except between a one and two factor solution (The eigenvalues greater than 


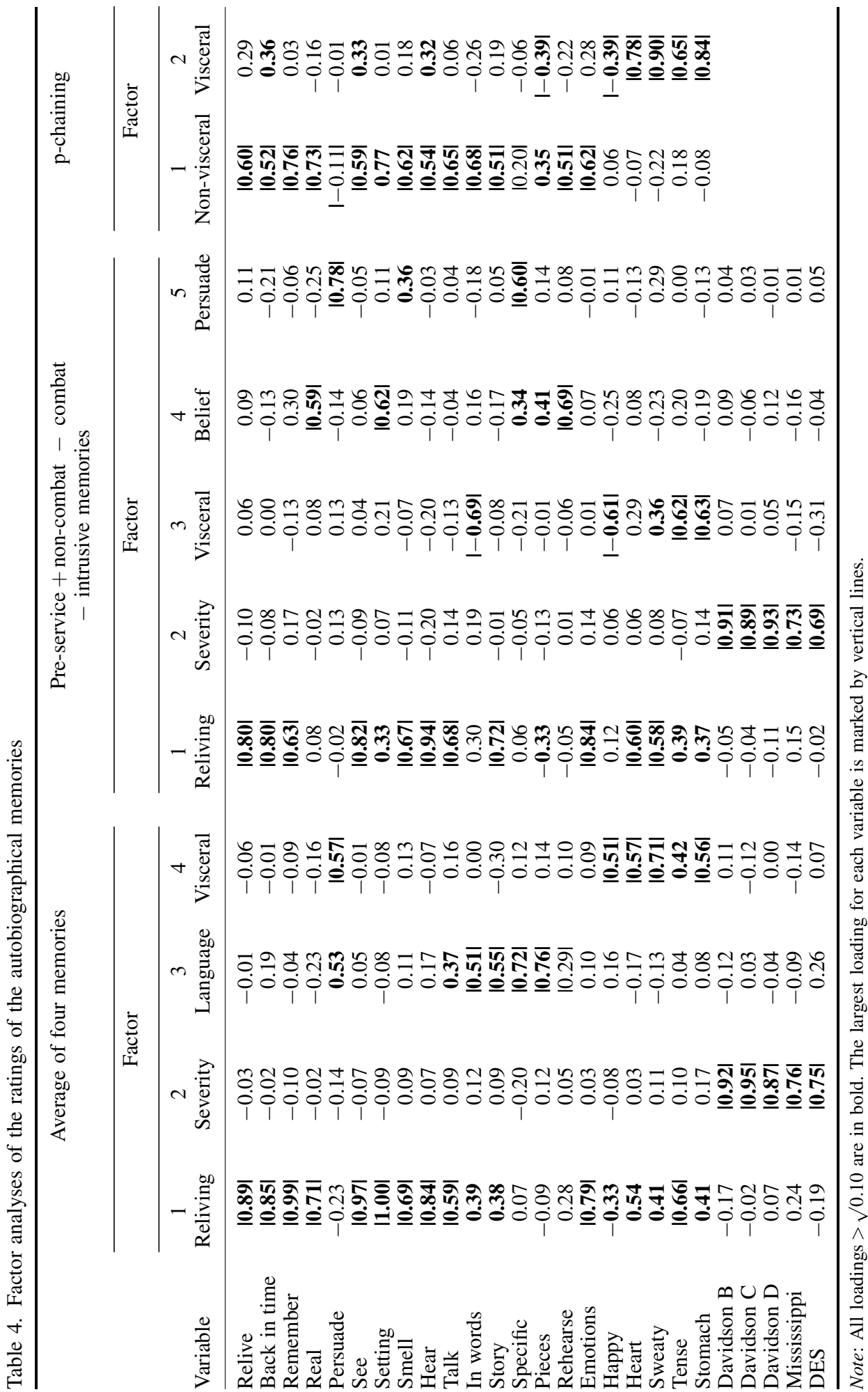


Table 5. Inter-factor correlations and variance explained

\begin{tabular}{|c|c|c|c|c|c|c|c|c|c|c|c|}
\hline \multirow[b]{3}{*}{ Factor } & \multicolumn{4}{|c|}{$\begin{array}{l}\text { Average of four } \\
\text { memories }\end{array}$} & \multicolumn{5}{|c|}{$\begin{array}{l}\text { Pre-service }+ \text { non-combat }- \\
\text { combat }- \text { intrusive memories }\end{array}$} & \multicolumn{2}{|c|}{$p$-chaining } \\
\hline & \multicolumn{4}{|c|}{ Factor } & \multicolumn{5}{|c|}{ Factor } & \multicolumn{2}{|c|}{ Factor } \\
\hline & 1 & 2 & 3 & 4 & 1 & 2 & 3 & 4 & 5 & 1 & 2 \\
\hline 1 & 1.00 & & & & 1.00 & & & & & 1.00 & \\
\hline 2 & 0.38 & 1.00 & & & 0.13 & 1.00 & & & & 0.63 & 1.00 \\
\hline 3 & 0.20 & 0.19 & 1.00 & & 0.35 & -0.06 & 1.00 & & & & \\
\hline 4 & 0.31 & 0.36 & 0.14 & 1.00 & 0.29 & -0.18 & 0.09 & 1.00 & & & \\
\hline 5 & & & & & 0.00 & 0.07 & -0.06 & -0.05 & 1.00 & & \\
\hline Variance $^{1}$ & 7.14 & 3.00 & 2.33 & 1.83 & 5.14 & 3.43 & 1.86 & 1.71 & 1.43 & 3.26 & 2.15 \\
\hline
\end{tabular}

${ }^{1}$ Variance explained eliminating other factors.

1.0 were $11.83,3.16,2.22,1.51 ; 7.69,4.09,1.82,1.41,1.38$; and $8.04,1.43$, respectively). Unlike Table 3, the DTS total score was not included because it is the sum of the B, C, and $\mathrm{D}$ scores. Table 5 displays the correlations among factors and the variance explained by each. The first two factor analyses are standard, individual differences, factor analyses in which a single value is obtained for each participant for the rating scales across the four types of memories. They can therefore include individual differences measures as well as the rating scales. The first is based on the average of the ratings for the four types of memories and thus asks about the memories of our participants in general. The second subtracts from the sum of the ratings of the combat and intrusive memories the sum of the ratings of the pre-service and non-combat memories and thus asks about the change in properties with an increase in the trauma relatedness of the event. The third factor analysis is different in that it is based on the 200 memories rather than the 50 participants, using a technique called p-chaining because the data for several people are chained together (Cattell, 1952; Nesselroade \& Molenaar, 1999). For this reason the standardized test measures cannot be included in the third factor analysis. Instead of using the mean on each rating scale for each person as the basic data as was done in the first factor analysis, the mean on each rating scale for each person is subtracted from that person's four memories and the remainders used for the factor analysis. In this way individual differences in means are removed and only variation caused by difference in the types of memories remain. That is, the first and third factor analysis are independent in that each is based on information that the other does not have; only the first has the mean value for each person, the third has variation around that mean.

Several findings are common to all the factor analyses. When the standardized test measures are included they form their own factor. Similarly, the visceral emotion measures tend to form their own factor, though in the first two analyses they split their loadings between their own factor and the factor with emotion. Although we intended persuade and real to both be measures of belief, persuade appears to be a complex measure that does not load highly with real. Of theoretical interest, our cognitive measure of emotion, the degree to which the emotion in the memory is judged to be the same as in the event, always appears on the factor with the reliving measures.

Examining the first factor analysis, which is based on the average of four memories for each participant, the three variables intended to measure a sense of reliving, the three sensory variables, and the degree to which the emotion experienced was the same as at the 
event all loaded highest on the first factor. Thus, the first factor has our central measures of reliving. It also has real, setting, and moderate loadings of the visceral emotions. The standardized tests load highest on the second factor. Language and narrative load highest on the third factor, and this factor does not correlate highly with any of the others, again suggesting that narrative coherence may be a separate measure in terms of individual differences. Such a collection of language measures is consistent with a dissociation view in which language is used by some participants instead of sensory components. The fourth factor contains the visceral emotions and a positive loading of happy; people whose memories are more positive on the average, report more visceral responses.

Instead of examining the average of four memories, the second factor analysis examines how the memories trauma-related situations differ from other memories. Overall, the factor analysis is similar to the first one, but has interesting differences. The three variables intended to measure reliving, the three sensory variables, and the degree to which the emotion was the same all load highest on factor 1 . Thus, like factor 1 in the first factor analysis, it has our central measures of reliving, but does not contain measures of belief in the accuracy of the memory. It does have the highest loading of two visceral emotions and the highest loading on story, which is in the direction opposite that predicted by the hypothesis that increases in the trauma relatedness of the situation would lead to incoherence in the memory. Real and setting do not load on factor 1 but form their own factor with rehearse. The pairing of real and setting is common in our other work (Rubin, Schrauf, \& Greenberg, 2003). Persuade and specific also form their own factor, which makes sense in that the more a memory does not adhere to a standard script, the more one could be persuaded it did not occur exactly as remembered. Factor 3 has the highest loadings of two of the visceral emotions and negative loadings from in words and happy, indicating that as the situation becomes more trauma related remembering a memory in words decreases while having visceral responses and negative valence increase.

The p-chaining measure in the third factor analysis resulted in two factors. Most measures load highly on the first factor, with the visceral measures, happy, and pieces loading on the second. In contrast to the first individual difference factor analysis, however, happy has a negative loading. People who experience more visceral symptoms tend to report the average of their memories (two of which are from combat or come as intrusive memories) as being happier, but once this individual difference is removed memories that have more visceral symptoms are less happy. Pieces also has a negative loading; the stronger the report of visceral emotions, less parts of the memory are missing.

Overall, the factor analyses are consistent with our other analyses and let us examine the relations among our measures in more detail. In terms of our three theoretical issues, the three variables that measure reliving directly, the sensory variables, and the reinstatement of the original emotion consistently load on the same factor suggesting that participants, memories of situations that are more or less trauma related, and how memories vary within participants all vary on a general concept of reliving. The factor analyses provide the strongest evidence for a separation of the cognitive variable of the judgment of reliving of the same emotion and the visceral emotions. The two kinds of measure of emotion do not form one factor or part of a factor. For the first two factor analyses, which use participants as the units of analysis, the visceral emotions spilt between the factor with the cognitive measure of emotions and their own factor. For the third factor analysis, which uses memories as the units of analysis, the visceral and cognitive measures of emotion load on separate factors. Finally, again we find no evidence for the fragmentation or incoherence 
hypothesis. Story loads positively on the factor containing the reliving variables. For our three factor analyses, respectively, this means that 1) participants with higher reliving scores judge their memories to be more coherent, 2) situations that are more trauma related have more reliving and more coherence, and 3) memories judged to have more of a sense of reliving are judged as more coherent within individuals. Pieces either does not have high loadings on the reliving factor or has ones inconsistent with a hypothesis of increased incoherence with increased reliving.

\section{DISCUSSION}

Memory impairment is a part of the definition of PTSD, but according to the diagnostic definitions (American Psychiatric Association, 1994), the impairment is primarily in autobiographical memory rather than memory in general and is in the phenomenology of the memory report rather than the memory's accuracy or reaction time as measured in laboratory studies of memory. We therefore examined the phenomenological properties of autobiographical memory reports in a sample of veterans diagnosed with PTSD to see how they varied over a variety of memories and with severity of PTSD symptoms in order to examine three theoretical issues. The analyses showed a reasonable, consistent pattern of relations among the basic phenomenological properties of autobiographical memory in a population of veterans diagnosed with PTSD. We found support for the generally held views that visceral and cognitive aspects of emotion can act in different ways and for an increased sense of reliving with more trauma-related memories and more severe PTSD symptoms. We found no support for, and evidence against, the view that with more trauma-related memories and with more severe PTSD symptoms the memories themselves become less coherent and more fragmented. In examining these questions we used the traditional experimental/cognitive psychological approach of varying the memories and averaging over people as well as the traditional individual differences approach of averaging over stimuli and varying the participants. Both analyses led to similar conclusions. Because we sampled only one population, veterans diagnosed with PTSD, our ability to generalize to other populations is limited. However, the fact that we could obtain such strong results with a restricted range of participants demonstrates that the effects are large, makes the findings more specific, and helps provide a balance for much of the literature on properties of autobiographical memory that tests undergraduates.

Returning to our three theoretical issues, we found no evidence in the literature, and added none here, that voluntary memories of traumatic events come with more of a sense of reliving than other memories of equal emotional intensity, though there is evidence that for involuntary memories, highly positive events are less frequent and have much more transient effects than traumatic memories (Berntsen, 2001). We do, however, provide evidence that with increases in emotional intensity or trauma relatedness, voluntary memories increase in reliving. We also demonstrate that with increases in PTSD symptoms, there is an increase in reliving for a sample of voluntary memories.

The extent to which our participants reported reexperiencing the emotions of the original event and the extent to which they reported visceral symptoms were related in reasonable ways. However, there were differences consistent with a cognitively accessible - visceral distinction. The measures of visceral emotions more consistently correlated with measures of PTSD severity and with dissociation. The same pattern occurred in a study of flashbulb memories in which a measure of visceral emotions, but not more 
cognitive judgments of emotion, taken the day after the September 11th attacks predicted later PTSD symptoms (Talarico \& Rubin, 2003). Similarly, in our factor analyses, the cognitive measure of reexperiencing the emotion loaded with other measures of reliving while the measures of visceral emotions tended to form their own factor or split between their own factor and the one with the highest loading of the cognitive measure of emotion.

We offer evidence against claims for a lack of coherence or fragmentation in memories of trauma or in people with more severe PTSD symptoms. We used ratings provided by the participants instead of obtaining extended narratives of the memories that could have been judged for coherence and fragmentation independent of the judgments of the participants. Thus we measure how the memories appear to the people who have them rather than to outside observers. This provides a complement to the work of Gray and Lombardo (2001) and others who used linguistic analyses of memories. Combined with the studies reviewed, we have strong evidence against the idea that memories for trauma are more fragmented or that such fragmentation is related to PTSD severity as measured by standardized tests. We cannot rule out fragmentation or a lack of coherence immediately after a trauma, but persisting fragmentation of the memory itself cannot be demonstrated. It still may be that the memory is 'fragmented' in the sense that some sensory and emotional aspects return in surprising strength and out of context to ongoing thoughts and activities or that traumatic events themselves are more fragmented and not as coherent as most events, but whether measured by rating scales of the participants, themselves or objective linguistic analyses there is no evidence for fragmentation internal to the structure of the memory. Combined with the studies noted earlier that showed PTSD symptoms correlated positively with the extent to which the memory was integrated centrally into one's concept of self (Berntsen et al., 2003; Byrne et al., 2001), the concept of fragmentation of memories in PTSD appears to be in need or reexamination.

\section{ACKNOWLEDGEMENTS}

We wish to than Dorthe Berntsen, Daniel Greenberg, Robert Schrauf, Jennifer Talarico, Kevin Weinfurt, and Daniel Wright for their comments on the paper. Funds were provided by NIH grant R01 MH62482 to JCB.

\section{REFERENCES}

American Psychiatric Association. (1994). Diagnostic and statistic manual of mental disorders (4th ed). Washington, DC: American Psychiatric Association.

Amir, N., Stafford, J., Freshman, M. S., \& Foa, E. B. (1998). Relationship between trauma narratives and trauma pathology. Journal of Traumatic Stress, 11, 385-392.

Baddeley, A. D. (1992). What is autobiographical memory? In M. A. Conway, D. C. Rubin, H. Spinnler, \& W. A. Wagenaar (Eds.), Theoretical perspectives on autobiographical memory (pp. 13-29). Dordrecht, The Netherlands: Kluwer Academic Publishers.

Bahrick, H. P. (1979). Maintenance of knowledge: questions about memory we forgot to ask. Journal of Experimental Psychology: General, 108, 296-308.

Bernstein, E. M., \& Putnam, F. W. (1986). Development, reliability and validity of a dissociation scale. Journal of Nervous and Mental Disease, 174, 727-734.

Berntsen, D. (2001). Involuntary memories of emotional events. Do memories of traumas and extremely happy events differ? Applied Cognitive Psychology, 15, 135-158. 
Berntsen, D., Willert, M., \& Rubin, D. C. (2003). Splintered memories or vivid landmarks? Reliving and coherence of traumatic memories in PTSD. Applied Cognitive Psychology, 17, 675-693.

Blake, D. D., Weathers, F. W., Nagy, L. M., Kaloupek, D. G., Gusman, F. D., Charney, D. S., \& Keane, T. M. (1995). The development of a clinician-administered PTSD scale. Journal of Traumatic Stress, 8, 75-80.

Brewer, W. F. (1996). What is recollective memory? In D. C. Rubin (Ed.), Remembering our past: Studies in autobiographical memory (pp. 19-66). Cambridge: Cambridge University Press.

Brewin, C. R., Dalgleish, T., \& Joseph, S. (1996). A dual representation theory of Posttraumatic stress disorder. Psychological Review, 103, 670-686.

Brown, R., \& Kulik, J. (1977). Flashbulb memories. Cognition, 5, 73-99.

Byrne, C. A., Hyman, I. E., \& Scott, K. L. (2001). Comparisons of memories for traumatic events and other experience. Applied Cognitive Psychology, 15, S119-S134.

Carlson, E. B., \& Putnam, F. W. (1993). An update on the Dissociative Experiences Scale. Dissociation, 6, 16-27.

Cattell, R. B. (1952). The three basic factor-analytic research designs-their interrelations and derivatives. Psychological Bulletin, 49, 499-520.

Christianson, S.-А. (1992). The handbook of emotion and memory: Research and theory. Hillsdale NJ: Lawrence Erlbaum Associates, Publishers.

Christianson, S.-Å., \& Nilsson, L.-G. (1989). Hysterical amnesia: a case of aversively motivated isolation of memory. In T. Archer, \& L. G. Nilsson (Eds.), Aversion, avoidance and anxiety (pp. 289-310). Hillsdale NJ: Lawrence Erlbaum.

Christianson, S.-Å., \& Safer, M. A. (1996). Emotional events and emotions in autobiographical memories. In D. C. Rubin (Ed.), Remembering our past: Studies in autobiographical memory (pp. 218-243). Cambridge: Cambridge University Press.

Conway, M. A., \& Dewhurst, S. A. (1995). The self and recollective experience. Applied Cognitive Psychology, 9, 1-19.

Cronbach, L. J. (1957). Two disciplines of scientific psychology. American Psychologist, 12, 671-684.

Davidson, J. R. T., Book, S. W., Colket, J. T., Tupler, L. A., Roth, S., David, D., Hertzberg, M., Mellman, T., Beckham, J. C., Smith, R. D., Davison, R. M., Katz, R., \& Feldman, M. E. (1997). Assessment of a new self-rating scale for posttraumatic stress disorder: the Davidson Trauma Scale. Psychological Medicine, 27, 153-160.

Elliott, D. M. (1997). Traumatic events: prevalence and delayed recall and the general population. Journal of Consulting and Clinical Psychology, 65, 811-820.

Farah, M. J., Hammond, K. M., Levine, D. N., \& Calvanio, R. (1988). Visual and spatial mental imagery: dissociable systems of representation. Cognitive Psychology, 20, 439-462.

Foa, E. B., \& Kozak, M. J. (1986). Emotional processing of fear: exposure to corrective information. Psychological Bulletin, 99, 20-35.

Foa, E. B., Molnar, C., \& Cashman, L. (1995). Change in rape narratives during exposure therapy for Posttraumatic stress disorder. Journal of traumatic stress, 8, 675-690.

Gardiner, J. M., Ramponi, C., \& Richardson-Klavehn, A. (1998). Experiences of remembering, knowing, and guessing. Consciousness and Cognition, 7, 1-26.

Gray M. J., \& Lombardo, T. W. (2001). Complexity of trauma narratives as an index of fragmented memory in PTSD: a critical analysis. Applied Cognitive Psychology, 15, S171-S185.

Greenberg D. L., \& Rubin, D. C. 2003. The neuropsychology of autobiographical memory. Cortex, 39, 687-728.

Hirshman, E., \& Lanning, K. (1999). Is there a special association between self judgments and conscious recollection? Applied Cognitive Psychology, 13, 29-42.

Horowitz, M. J. (1975). Intrusive and repetitive thought after experimental stress. Archives of General Psychiatry, 32, 1457-1463.

Horowitz, M. J., \& Reidbord, S. P. (1992). Memory, emotion, and response to trauma. In S.- $\AA$. Christianson (Ed.), The handbook of emotion and memory. Research and theory (pp. 343-357). Hillsdale, New Jersey: Lawrence Erlbaum.

Hyman, I. E. Jr., Gilstrap, L. L., Decker, K., \& Wilkinson, C. (1998). Manipulating remember and know judgments of autobiographical memories: an investigation of false memory creation. Applied Cognitive Psychology, 12, 371-386. 
Johnson, M. K., Foley, M. A., Suengas, A. G., \& Raye, C. L. (1988). Phenomenal characteristics of memories for perceived and imagined autobiographical events. Journal of Experimental Psychology: General, 117, 371-376.

Keane, T. M., Caddell, J. M., \& Taylor, K. L. (1988). Mississippi scale for combat-related posttraumatic stress disorder: three studies in reliability and validity. Journal of Consulting and Clinical Psychology, 56, 85-90.

Keane, T. M., Kolb, L. C., Kaloupek, D. G., Orr, S. P., Blanchard, E. B., Thomas, R. G., Hsieh, R. Y., \& Lavori, P. W. (1998). Utility of psychophysiological measurement in the diagnosis of posttraumatic stress disorder: results from a Department of Veterans Affairs Cooperative Study. Journal of Consulting and Clinical Psychology, 66, 914-923.

Kolb, L. C., \& Mutalipassi, L. R. (1982). The conditioned emotional response. A sub-class of the chronic and delayed Post-traumatic stress disorder. Psychiatric Annals, 12, 979-987.

Lambie, J. A., \& Marcel, A. J. (2002). Consciousness and the varieties of emotional experience: a theoretical framework. Psychological Review, 109, 219-259.

LeDoux, J. E. (1989). Indelibility of subcortical emotional memories. Journal of Cognitive Neuroscience, 1, 238-243.

McNally, R. J., Lasko, N. B., Macklin, M. L., \& Pitman, R. K. (1995). Autobiographical memory disturbance in combat-related Post-traumatic stress disorder. Behavioral Research and Therapy, 33, 619-630.

Nesselroade, J. R., \& Molenaar, P. C. M. (1999). Pooling lagged covariance structures based on short, multivariate time series for dynamic factor analysis. In R. H. Hoyle (Ed.), Statistical strategies for small sample research (pp. 224-250). Thousand Oaks CA: Sage Publications.

Nijenhuis, E. R. S., \& Van der Hart, O. (1999). Forgetting and reexperiencing trauma. In J. Goodwin, \& R. Cittias (Eds.), Splintered reflections: Images of the body in the trauma (pp. 39-65). New York: Basic Books.

Pitman, R. K. (1988). Post-traumatic stress disorder conditioning, and network theory. Psychiatric Annals, 18, 182-189.

Pitman, R. K., Orr, S. P., \& Steketee, G. S. (1989). Psychophysiological investigations of posttraumatic stress disorder imagery. Psychopharmacology Bulletin, 25, 426-431.

Pitman, R. K., Orr, S. P., Forgue, D. F., Altman, B., de Jong, J. B., \& Herz, L. R. (1990). Psychophysiological responses to combat imagery of Vietnam veterans with posttraumatic stress disorder versus other anxiety disorder. Journal of Abnormal Psychology, 99, 49-54.

Porter, S., \& Birt, A. R. (2001). Is traumatic memory special? A comparison of traumatic memory characteristics with memory for other emotional life experiences. Applied Cognitive Psychology, 15, S101-S118.

Read, D. J., \& Winograd, E. (1998). Introduction. Applied Cognitive Psychology, 12, S1-S4.

Reisberg, D. (Ed.). (1992). Auditory imagery. Hillsdale NJ: Lawrence Erlbaum Associates.

Robinson, J. A. (1996). Perspective, meaning, and remembering. In D. C. Rubin (Ed.), Remembering our past: Studies in autobiographical memory (pp. 199-217). Cambridge: Cambridge University Press.

Ross M., Buehler, R., \& Karr, J. W. (1998). Assessing the accuracy of conflicting autobiographical memories. Memory \& Cognition, 26, 1223-1244.

Rubin, D. C. (1995a). Memory in oral traditions: The cognitive psychology of epic, ballads, and counting out rhymes. New York: Oxford University Press.

Rubin, D. C. (1995b). Stories about stories. In R. S., Wyer Jr. (Ed.), Knowledge and memory: The real story (pp. 153-164). Hillsdale, NJ: Lawrence Erlbaum Associates.

Rubin, D. C. (1998). Beginnings of a theory of autobiographical remembering. In C. P. Thompson, D. J. Herrmann, D. Bruce, J. D. Reed, D. G. Payne, \& M. P. Toglia (Eds.), Autobiographical memory: Theoretical and applied perspectives (pp. 47-67). Mahwah NJ: Erlbaum.

Rubin, D. C., \& Greenberg, D. L. (2003). The role of narrative in recollection: A view from cognitive and neuropsychology. In G. Fireman, T. McVay, \& O. Flanagan (Eds.), Narrative and consciousness: Literature, psychology, and the brain. (pp. 53-85). New York: Oxford University Press.

Rubin, D. C., Groth, L., \& Goldsmith, D. (1984). Olfactory cuing of autobiographical memory. American Journal of Psychology, 97, 493-507.

Rubin, D. C., Schrauf, R. W., \& Greenberg, D. L. (2003). Belief and recollection of autobiographical memories. Memory \& Cognition, 31, 887-901. 
Rybash, J. M., \& Monaghan, B. E. (1999). Episodic and semantic contributions to older adults' autobiographical recall. Journal of General Psychology, 126, 85-96.

Schrauf, R. W. (2000). Bilingual autobiographical memory: experimental studies and clinical cases. Culture \& Psychology, 6, 387-417.

Schrauf, R. W., \& Rubin, D. C. (1998). Bilingual Autobiographical memory in older adult immigrants: a test of cognitive explanations of the reminiscence bump and the linguistic encoding of memories. Journal of Memory and Language, 39, 437-457.

Schrauf, R. W., \& Rubin, D. C. (2000). Identification of internal languages of retrieval: the bilingual encoding of memories for the personal past. Memory \& Cognition, 28, 616-623.

Sheen, M., Kemp, S., \& Rubin, D. C. (2001). Twins dispute memory ownership: a new false memory phenomenon. Memory \& Cognition, 29, 779-788.

Talarico, J. M., \& Rubin, D. C. (2003). Confidence, not consistency, characterizes flashbulb memories. Psychological Science, 14, 455-461.

Tromp, S., Koss, M. P., Figueredo, A. J., \& Tharan, M. (1995). Are rape memories different? A comparison of rape, other unpleasant and pleasant memories among employed women. Journal of Traumatic Stress, 8, 607-627.

Tulving, E. (1983). Elements of episodic memory. Oxford: Oxford University Press.

Tulving, E. (1985). Memory and consciousness. Canadian Psychology, 25, 1-12.

Van der Hart, O., Van der Kolk, B. A., \& Boon, S. (1998). Treatment of dissociative disorders. In J. D. Bremner, \& C. R. Marmar (Eds.), Trauma, memory and dissociation (pp. 253-283). Washington, DC: American Psychiatric Press.

Van der Kolk, B. A., \& Fisler, R. (1995). Dissociation and the fragmentary nature of traumatic memories: overview and exploratory study. Journal of Traumatic Stress, 8, 505-525.

Wheeler, M. A., Stuss, D. T., \& Tulving, E. (1997). Toward a theory of episodic memory: the frontal lobes and autonoetic consciousness. Psychological Bulletin, 121, 331-354.

Wright, D. B. (1998). Modelling clustered data in autobiographical memory research: the multilevel approach. Applied Cognitive Psychology, 12, 339-357.

Wright, D. B., \& Livingston-Raper, D. (2002). Memory distortion and dissociation: Exploring the relationship in a non-clinical sample. Journal of Trauma and Dissociation, 3, 97-109. 